\title{
Fractalkine Mediates Communication between Pathogenic Proteins and Microglia: Implications of Anti-Inflammatory Treatments in Different Stages of Neurodegenerative Diseases
}

\author{
Nicole M. Desforges, Michaeline L. Hebron, Norah K. Algarzae, \\ Irina Lonskaya, and Charbel E.-H. Moussa \\ Department of Neuroscience, Georgetown University Medical Center, Washington, DC 20057, USA
}

Correspondence should be addressed to Charbel E.-H. Moussa, cem46@georgetown.edu

Received 24 May 2012; Revised 3 July 2012; Accepted 5 July 2012

Academic Editor: Jesús Avila

Copyright (C) 2012 Nicole M. DesForges et al. This is an open access article distributed under the Creative Commons Attribution License, which permits unrestricted use, distribution, and reproduction in any medium, provided the original work is properly cited.

\begin{abstract}
The role of inflammation in neurodegenerative diseases has been widely demonstrated. Intraneuronal protein accumulation may regulate microglial activity via the fractalkine (CX3CL1) signaling pathway that provides a mechanism through which neurons communicate with microglia. CX3CL1 levels fluctuate in different stages of neurodegenerative diseases and in various animal models, warranting further investigation of the mechanisms underlying microglial response to pathogenic proteins, including Tau, $\beta$-amyloid (A $\beta)$, and $\alpha$-synuclein. The temporal relationship between microglial activity and localization of pathogenic proteins (intra- versus extracellular) likely determines whether neuroinflammation mitigates or exacerbates disease progression. Evidence in transgenic models suggests a beneficial effect of microglial activity on clearance of proteins like A $\beta$ and a detrimental effect on Tau modification, but the role of CX3CL1 signaling in $\alpha$-synucleinopathies is less clear. Here we review the nature of fractalkine-mediated neuronmicroglia interaction, which has significant implications for the efficacy of anti-inflammatory treatments during different stages of neurodegenerative pathology. Specifically, it is likely that anti-inflammatory treatment in early stages of disease during intraneuronal accumulation of proteins could be beneficial, while anti-inflammatory treatment in later stages when proteins are secreted to the extracellular space could exacerbate disease progression.
\end{abstract}

\section{Introduction}

Increased microglial activity facilitates beneficial responses to central nervous system (CNS) injuries, including phagocytosis of debris and clearance of apoptotic cells; however, unregulated microglial activity can lead to production of neurotoxic factors that worsen CNS pathology and cause neuronal degeneration [1-7]. Microglia constitute the main immune cells in the CNS and provide innate immunity under physiological conditions and adaptive immunity under stress, promoting inflammation in response to various signals from apoptotic cells [1-4]. The phenotype of CNS resident macrophages is considered activated and designated M1 or "classical activation," which describes the proinflammatory phenotypic response. M2 or "alternative activation" describes phenotypic responses to cytokines, such as Interleukin-(IL-) 4 and IL-13 [8]. In many neurodegenerative diseases, persistent injury (such as intraneuronal protein accumulation) promotes the production of proinflammatory molecules (Figure 1), like tumor necrosis factor (TNF)- $\alpha$, Interleukin (IL)- $1 \beta$, IL-6, reactive oxygen species (ROS), and nitric oxide (NO) [9]. Proinflammatory factors activate microglia $[10,11]$, which may remove not only apoptotic or damaged neurons, but also healthy neurons, aggravating the pathogenic process [5].

The inflammatory response is generally localized to areas of CNS injury via communication between immune cells and stressed neurons. Innate inflammation is reported 


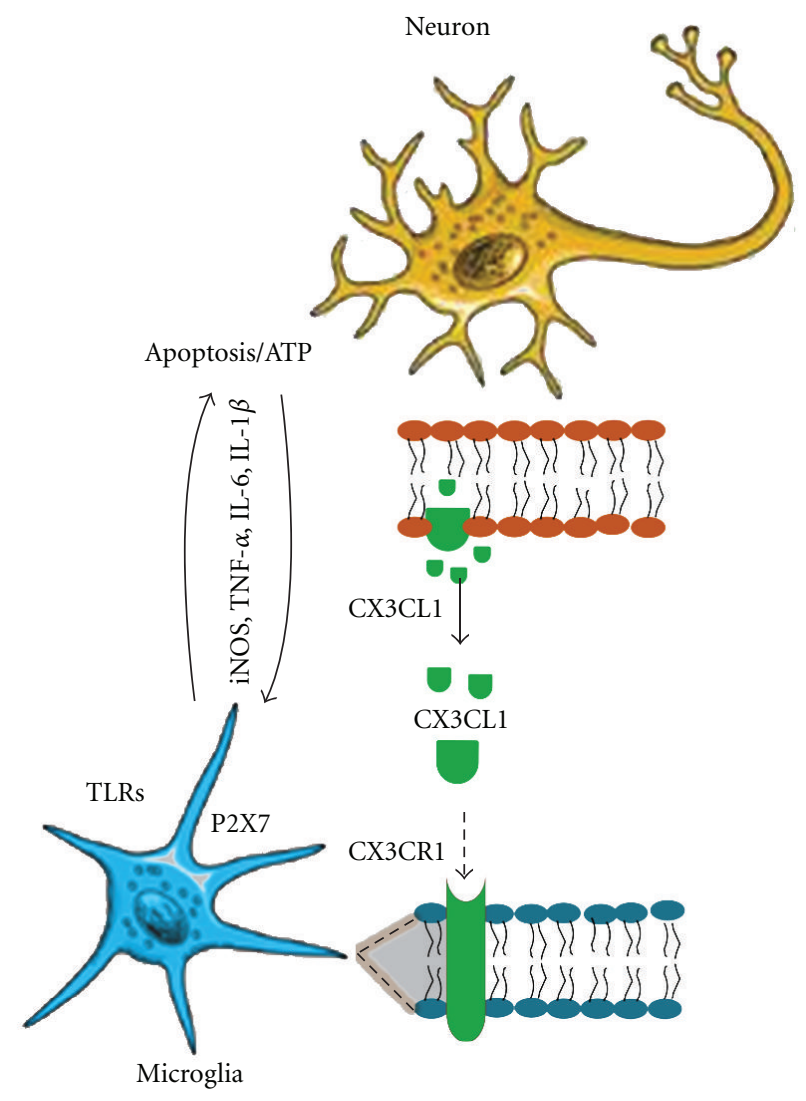

Figure 1: Initiation of inflammatory response following intraneuronal protein accumulation. Intraneuronal accumulation of pathogenic proteins causes ATP release by apoptotic neurons to activate purinergic microglia $\mathrm{P} 2 \mathrm{X} 7$ receptors or TLRs. Activated microglia release proinflammatory cytokines (TNF- $\alpha$, IL-16, IL-1) and iNOS to activate astrocytes (via MCP-1 chemotaxis) and increase apoptosis in stressed neurons. To initiate a neuroprotective immune response, injured neurons may communicate via fractalkine (CX3CR1) and suppress inflammation.

in Alzheimer's disease (AD), Parkinson's disease (PD), and the Tauopathies (reviewed in [12]). In the healthy brain, microglia have a resting "deactivated" phenotype (ramified) [10]. Activated microglia are present in human postmortem brain tissues of patients with tauopathies, including $\mathrm{AD}$, frontotemporal dementia with parkinsonism linked to chromosome-17 (FTDP), progressive supranuclear palsy (PSP), and corticobasal degeneration (CBD) [13-15]. Also associated with neurodegeneration in these diseases are hyperphosphorylated Tau (p-Tau) deposits [16-23]. It has been demonstrated in animal models of AD that the endotoxin lipopolysaccharide (LPS) promotes both inflammation and the accumulation of p-Tau [24] and that suppression of microglial activity prolongs survival in FTDP-associated P301L transgenic mice [25]. Our laboratory has previously shown a differential increase in microglial activity in response to accumulation of $\mathrm{p}$-Tau in lentiviral wild type Tau versus mutant P301L mice at 1 month after-injection [26]. Cell culture models also demonstrate that proinflammatory cytokines can induce p-Tau [27-29]. These data suggest that microglial activity aggravates $\mathrm{p}$-Tau through a common underlying mechanism moderating communication between microglia and neurons. Determining how this mechanism is temporally altered in response to $\mathrm{p}$-Tau is critical to understanding the beneficial or detrimental role of microglial activity in different stages of disease pathology [30-32].

\section{Fractalkine in Human Disease and Animal Models of Neurodegeneration}

A central question in current research pertains to how communication between microglia and neurons, in which pathogenic proteins accumulate, affects the progression of inflammation. One inducer through which neurons and microglia can communicate to regulate inflammation is fractalkine (CX3CL1) (Figure 1). CX3CL1 is a 373-amino acid protein that has a chemokine domain located on top of a mucin-like stalk $[33,34]$. Neurons secrete CX3CL1 [34], which exists in both membrane-bound and soluble forms [35]. The membrane-bound CX3CL1 can serve as an adhesion molecule for leukocytes expressing the fractalkine receptor (CX3CR1) [36] and soluble CX3CL1 can function as both a proinflammatory chemoattractant that activates receptive inflammatory cells $[33,37]$ and an anti-inflammatory [38], neuroprotective agent that reduces neuronal apoptosis [39]. The relationship between soluble CX3CL1 in peripheral blood and inflammatory diseases of the CNS is unclear. Several findings suggest that deletion of CX3CR1 increases microglial activity in various models of acute and chronic neuronal injury [40-43]. Fluctuations in CX3CL1 levels are also observed in many neurodegenerative diseases. Increased levels of serum CX3CL1 are reported in patients with multiple sclerosis $[39,44]$, traumatic brain injury [45], and human immunodeficiency virus (HIV) with CNS complications [46], but increased levels of serum CX3CL1 are not observed in patients with Guillain-Barré Syndrome and viral and bacterial meningitis [44]. Genetic variants with reduced levels of CX3CR1 are linked to agerelated macular degeneration in humans [47].

CX3CL1 and its cognate receptor CX3CR1 may play an important role in immunoregulation in animal models of neurodegeneration. CX3CL1 expression is decreased in the cerebral cortex and hippocampus in the aged brains of amyloid precursor protein (APP) transgenic mice [48]. Decreased CX3CL1 levels are also observed in aged AD transgenic mouse models (Tg2576) in association with increased $\mathrm{A} \beta$ levels [48]. Microglial activity was increased while the levels of $\mathrm{A} \beta$ load and CX3CR1 were decreased in $\mathrm{MyD}^{-/-}$mice, suggesting CX3CL1 involvement in $\mathrm{A} \beta$ clearance [49]. CX3CR1 deficiency leads to decreased levels of $\mathrm{A} \beta$ deposition and protects against $\mathrm{A} \beta$ toxicity in transgenic mouse models of $\mathrm{AD}[50,51]$. LPS induces p-Tau of both endogenous and transgene-derived Tau in nontransgenic mice and in a humanized mouse model of Tauopathy, depending on LPS dose and CX3CR1 deficiency [40]. Additionally, impairment of CX3CL1 signaling pathway leads to deterioration in cognitive function and synaptic 
plasticity via alteration of IL- $1 \beta$ function [52]. Although CX3CR1 deficiency exacerbates AD-related neuronal and behavioral pathologies in mice overexpressing human $A \beta$, these effects are likely to be associated with the level of cytokine production and not $A \beta$ plaque load, suggesting that alteration of proinflammatory factors, including TNF- $\alpha$ and IL-6 may modulate CX3CL1 signaling [43]. Conversely, production of NO, IL- 6 , and TNF- $\alpha$ may be inhibited by CX3CL1 $[53,54]$.

Exogenous CX3CL1 is neuroprotective in some other models of neuroinflammation $[55,56]$, and disruption of CX3CL1-CX3CR1 communication by deletion of the CX3CR1 gene causes neurotoxicity in mouse models of systemic inflammation, $\mathrm{PD}$, and amyotrophic lateral sclerosis [57] but protects against neuronal loss in a mouse model of focal cerebral ischemia [58]. CX3CR1 knockout mice show more toxicity and substantia nigra (SN) degeneration in response to LPS treatment following administration of 1methyl-4-phenyl-1,2,3,6-tetrahydropyridine (MPTP), a neurotoxic precursor of 1-methyl-4-phenylpyridinium (MPP+) [57]. Together, these studies suggest altered microglial activity through CX3CL1 signaling, which may play a direct role in immunoregulation depending upon the CNS insult. CX3CL1-CX3CR1 signaling is therefore a possible mediator of communication between injured neurons and microglia and may play a significant role in the regulation of microglial activity in response to pathogenic protein accumulation in early, or protein secretion, in later stages of disease.

\section{Intraneuronal $\mathbf{A} \beta$ and Inflammation in Early Stages of AD}

A primary feature of $\mathrm{AD}$ is the presence of extracellular aggregates of $\mathrm{A} \beta$ peptide (plaques) and intracellular inclusions (tangles) containing p-Tau [59-61]. Variants of $A \beta$ peptide, including $A \beta 42$ and $A \beta 40$, are produced by the cleavage of APP and subsequent cleavage of an intermediate fragment, APP C-terminal fragments (CTFs) [62]. Cleavage of APP at an alternative site within the $A \beta$ region by the cleaving enzyme $\alpha$-secretase precludes $A \beta$ formation $[63,64]$. The causal association between mutations in APP and the onset of familial $\mathrm{AD}$ supports the role of $\mathrm{A} \beta$ in $\mathrm{AD}$ pathogenesis [65]. It is likely that in the early stages of disease, $\mathrm{A} \beta$ accumulates intraneuronally prior to the formation of extracellular plaques [66]. It is also likely that the intracellular pool of $\mathrm{A} \beta$ is externalized as neurons die, contributing to the formation of senile plaques [67-70]. The presence of intraneuronal $A \beta$ is significant in that such a presence constitutes a preplaque stage of $\mathrm{AD}$ pathology. Our laboratory has previously shown that intraneuronal $\mathrm{A} \beta$ induces microglial and astrocyte activation and increases inflammatory markers in gene transfer models $[71,72]$. Furthermore, it has been shown that intraneuronal $\mathrm{A} \beta$ can cause apoptosis and cell death, which stimulate microglial and astrocyte activation independently of extracellular plaques [73]. These results implicate communication between microglia and $\mathrm{A} \beta$ expressing neurons in the onset of inflammation in AD. Inflammation has been associated with neurodegenerative disease etiology in $\mathrm{AD}$, in which $\mathrm{A} \beta$ and
Tau can act as inflammatory stimuli to promote microglial activity $[1,74-76]$. Therefore, inflammation in $\mathrm{AD}$ may arise not only from extracellular plaque formation, but also as a consequence of communication between microglia and $\mathrm{A} \beta$-expressing neurons. Accumulation of intraneuronal $\mathrm{A} \beta$ can induce damage to lysosomes and multivesicular bodies, leading to leakage of $A \beta$ from vesicles into the cytosol and activation of inflammatory mechanisms without extracellular accumulation of amyloid plaques. Several studies have suggested that manipulation of chemokines and/or their receptors may be a therapeutic target in neurodegenerative diseases, including $\mathrm{AD}$ [77-79]. Microglia treated with recombinant CX3CL1 or IL-34 partially protect against $\mathrm{A} \beta$ toxicity via enhancement of $\mathrm{A} \beta$ clearance and antioxidant production [80]. Significant differences in CX3CL1 levels were detected in a cohort of 51 patients with mild cognitive impairment (MCI), $51 \mathrm{AD}$ patients and 57 controls [81]. However, the increase in plasma CX3CL1 levels is not congruent with tissue levels, which are decreased in the hippocampus and frontal cortex of advanced AD cases [43], suggesting variable roles of CX3CL1 in different stages of $\mathrm{AD}$ pathogenesis. The level of plasma soluble fractalkine was significantly higher in MCI and moderate $\mathrm{AD}$ patients compared to severe $\mathrm{AD}$, suggesting that higher levels of soluble plasma fractalkine is associated with greater cognitive impairment [81]. Therefore, the fractalkine signaling pathway that mediates communication between microglia and neurons is deficient in $\mathrm{AD}$ brains and downregulated by $\mathrm{A} \beta$.

\section{Fractalkine in PD-Related Inflammation}

The characteristics of PD include death of dopaminergic neurons in the $\mathrm{SN}[50,58,82]$ and formation of Lewy bodies (LBs) [83-92], or inclusions comprised mainly of $\alpha$-synuclein [83-99]. The simultaneous occurrence of $\alpha$ synuclein and Tau pathology is observed in multiple system atrophy (MSA), though the mechanisms underlying a possible connection between the two proteins are unknown $[100,101]$. Early onset familial PD arises from mutations in the autosomal recessive genes PARKIN, PTEN-induced kinase-1 (PINK1), and DJ-1 [94] while late onset PD is associated with dominantly-inherited mutations in leucinerich repeat kinase 2 (LRRK2) and $\alpha$-synuclein.

Aggregation of $\alpha$-synuclein is implicated in the activation of microglia and subsequent inflammation associated with PD. It was previously thought that $\alpha$-synuclein-related pathology was confined to within neurons, but recent research suggests that microglia are activated following the release of $\alpha$-synuclein aggregates into the extracellular space by apoptotic cells [102]. However, extracellular $\alpha$ Synuclein has not been found in PD brains. Aggregated forms of $\alpha$-synuclein induce microglial activation $[99,103]$. Several microglia-derived inflammatory factors (ROS, NO, TNF- $\alpha$, and IL- $1 \beta$ ), as well as LPS, promote death of dopaminergic neurons [104-106]. The phagocytosis of $\alpha$ synuclein by microglia induces NADPH oxidase activity and the production of ROS [103]. These neurotoxic effects signify a contributory role of microglia and inflammation in PD 
pathology. Inflammation has also been detected in PD brains lacking LBs, such as parkin-linked autosomal recessive early onset PD [9]. These cases, as well as the role of Tau as a risk factor for $\mathrm{PD}$, suggest that additional mechanisms regulate inflammation. For example, CX3CL1 suppresses microglial activation and protects against neuronal loss and striatal lesion in 6-hydroxydopamine (6-OHDA) rat model of PD [107]. MPP+ increases neuronal CX3CL1 levels in rat SN, but administration of CX3CR1 antagonists blocks PD-like pathology, including loss of dopaminergic neurons and motor behavior [108], suggesting that fractalkine can modulate microglial activation in PD models. Deletion of CX3CR1 aggravates microglial neurotoxicity in response to LPS in the MPTP model of PD and in the superoxide dismutase 1 (SOD1) G93A model of ALS [57], suggesting that CX3CL1 signaling may limit microglial toxicity [57]. The level of plasma soluble CX3CL1 also correlates positively with disease severity and progression in human PD patients, suggesting that CX3CL1 can be used as a biomarker to differentiate between neurodegenerative diseases [109].

\section{The Effects of Microglial Activation Depend on Disease Stage}

Whether inflammation rescues or exacerbates cell death in neurodegenerative disease likely depends on the stage of disease progression. Microglial activation facilitates the removal of apoptotic cells and toxins from the CNS, releasing neurotrophic factors that aid in repair following injury [5]. However, microglia also release inflammatory markers that can induce apoptosis. The apparent ambivalence of increased microglial activity is associated with unsuccessful attempts to provide anti-inflammatory treatment in human clinical trials. Preliminary clinical trials in which nonsteroidal antiinflammatory drugs (NSAIDs) were administered before the development of neurodegeneration suggested that disease risk was reduced by inhibition of the immune response [110, 111]. However, later trials found that anti-inflammatory drugs were harmful in AD patients [110]. These conflicting data reflect the current lack of understanding of the role of the immune response in CNS diseases and point to the importance of the temporal relationship between the disease stage and the anti-inflammatory intervention.

The timing of the immune response in relation to disease progression complicates the use of anti-inflammatory treatment in various CNS diseases. For example, the permanence of brain damage following stroke or ischemia depends on the activity of proinflammatory cytokines, the activation of microglia, and the recruitment of leukocytes [112, 113]. It has been found that inhibiting TNF- $\alpha$ and IL-1, which mediate postischemic activity by attracting leukocytes to the injury or by damaging cells directly, confers neuroprotection in animal models of stroke $[112,113]$. In $\mathrm{AD}$ models, the involvement of innate immunity via microglial activation and phagocytosis of $\mathrm{A} \beta$ renders anti-inflammatory therapy particularly relevant to the study of $\mathrm{AD}$ [114-116]. In AD patients, however, deficits in Toll-like receptors (TLRs) expression inhibit the removal of $\mathrm{A} \beta$ from the brain and result in lack of $\mathrm{A} \beta$ clearance by macrophages [117], and TLR2 deficiency in AD mouse models is associated with severe cognitive impairment [118]. In addition to antiinflammatory treatment, intervention in the hematopoietic system has been suggested as a possible model of treatment for $\mathrm{AD}$. The administration of macrophage colonystimulating factor, a hematopoietic cytokine, to mouse microglia promotes degradation of internalized $\mathrm{A} \beta$ in vitro [119] and protects against cognitive decline in vivo when administered prior to the development of learning and memory deficits [120], supporting the importance of timing of anti-inflammatory treatment relative to disease progression. Taken together, these findings support the targeting of innate immune cells as a therapeutic approach for $\mathrm{AD}$ and other neurodegenerative diseases. However, conflicting data from clinical trials necessitate further investigation of the role of the immune response in disease development and progression.

\section{Putting It into Perspective}

Research on the suppression of microglial activity has been actively pursued with limited success [121] and strategies to manipulate the protective role of microglia - the detection and removal of apoptotic cells - have not been fully investigated [122-124]. These strategies warrant further research, as apoptotic cells that enter secondary necrosis [125] and trigger inflammation $[126,127]$ increase tissue damage. In this context, the role of CX3CL1 in mediating communication between preapoptotic neurons and microglia becomes greatly important. Such intervention would be relevant in early stages of disease progression, during which intracellular accumulation of pathogenic proteins anticipates apoptosis and the formation of extracellular protein aggregates. In later stages of disease pathology, decreased CX3CL1 signaling may activate microglia and induce p-Tau (Figure 2), which exacerbates disease progression by promoting apoptosis. Additionally, the use of NSAIDs to restrain microglial activity may exacerbate pathology due to lack of phagocytic clearance of secreted extracellular amyloids, including $\alpha$-Synuclein, A $\beta$ and $\mathrm{p}$-Tau. In this context, targeting microglial activity in later disease stages may be detrimental and contributory to disease progression. However, targeting the CX3CL1 pathway in early disease stages could be beneficial, at least in delaying disease progression via restraint of microglial activity. Along this line of thought, NSAIDs administration could regulate key proinflammatory cytokines (Figure 2) that would modulate CX3CL1 signaling and microglial activity. It remains to be fully elucidated when and how alteration of proinflammatory markers may increase or decrease CX3CL1 signaling, which may either activate or suppress microglia. One possibility is increased CX3CL1 levels to restrain microglial activity and prevent the exacerbation of p-Tau damage. However, this intervention should be timed to avoid interference with microglial activity when patients progress into more advanced stages of disease, during which removal of extracellular deposits becomes necessary. Therefore, understanding the critical interplay 


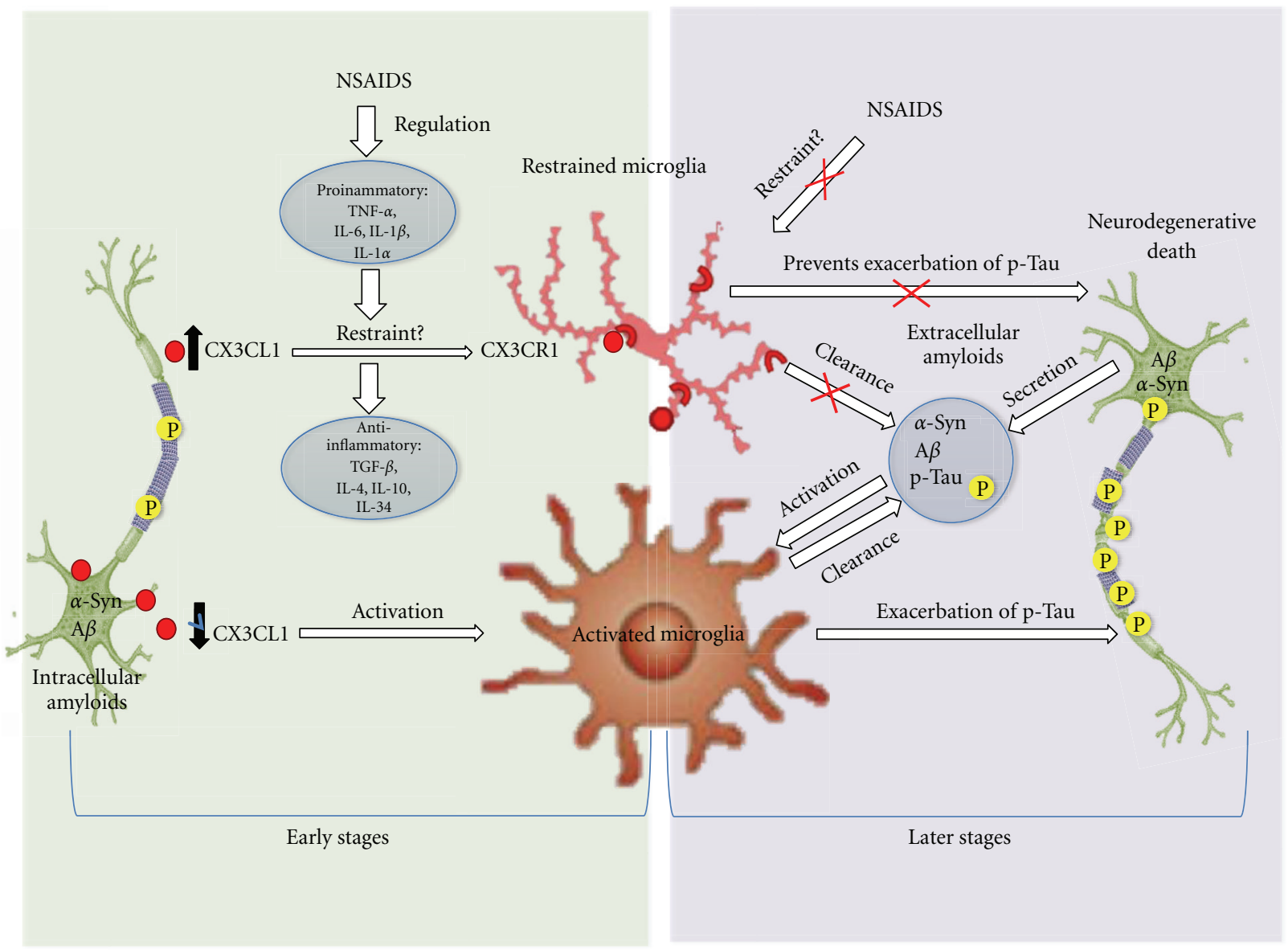

FIGURE 2: Modulation of CX3CL1 in early versus late disease stages. The success of anti-inflammatory treatment in neurodegenerative diseases likely depends on the stage of disease progression. Treatment with NSAIDS early in disease pathology may alter the levels of various proinflammatory markers, including TNF- $\alpha$, IL-6, IL- $1 \beta$, and IL- $1 \alpha$, and anti-inflammatory markers, including TGF- $\beta$, IL- 4 , IL-10, and IL-34. The changes in the levels of these cytokines may lead to altered CX3CL1 signaling, which would either increase microglial activity (if CX3CL1 were reduced) or restrain microglia (if CX3CL1 levels were increased). In later stages of disease, secretion of pathogenic proteins like A $\beta, \alpha$-synuclein, and p-Tau to the extracellular space increases microglial activation. Microglial activity promotes p-Tau, which destabilizes microtubules and leads to cell death. Treatment with NSAIDS in later stages of disease would likely be detrimental, as restraining microglia would weaken the immune response to remove extracellular protein aggregates.

between proinflammatory (TNF- $\alpha$, IL-6, IL- $1 \beta$, and IL- $1 \alpha$ ), anti-inflammatory cytokines (IL-10, TGF- $\beta$, IL-34, etc.), and fractalkine levels to modulate microglial activity is highly significant. Furthermore, whether the activation of microglia in the context of neurodegenerative disease is beneficial or detrimental may also depend upon the type of disease. Successful anti-inflammatory treatments of CNS diseases will likely be specific not only to the stage of disease pathology, but also to the type of disease. It has been found that many of the same cytokines are implicated in the pathology of $\mathrm{AD}, \mathrm{PD}$, and ALS despite distinct patterns of neuronal loss in each disease [9]. Previous literature presents contradictory evidence regarding the effects of targeting microglia in various CNS diseases. Glass et al. [128], for example, suggest that targeting microglia in PD and ALS is detrimental while other studies suggest that targeting microglia aids in $\mathrm{A} \beta$ clearance in $\mathrm{AD}$. Further investigation of the role of the inflammatory response in each disease will determine the potential for anti-inflammatory treatments. Here we suggest a temporally-defined strategy of intervention in which early targeting of CX3CL1 signaling slows disease progression and prevents p-Tau formation.

\section{Acknowledgments}

This work was supported by NIH Grant AG 30378 and Georgetown University support to C. E.-H. Moussa.

\section{References}

[1] R. M. Ransohoff and V. H. Perry, "Microglial physiology: unique stimuli, specialized responses," Annual Review of Immunology, vol. 27, pp. 119-145, 2009.

[2] W. J. Streit, "Microglia as neuroprotective, immunocompetent cells of the CNS," GLIA, vol. 40, no. 2, pp. 133-139, 2002. 
[3] O. Takeuchi and S. Akira, "Pattern recognition receptors and inflammation,” Cell, vol. 140, no. 6, pp. 805-820, 2010.

[4] F. Di Virgilio, S. Ceruti, P. Bramanti, and M. P. Abbracchio, "Purinergic signalling in inflammation of the central nervous system," Trends in Neurosciences, vol. 32, no. 2, pp. 79-87, 2009.

[5] G. C. Brown and J. J. Neher, "Inflammatory neurodegeneration and mechanisms of microglial killing of neurons," Molecular Neurobiology, vol. 41, no. 2-3, pp. 242-247, 2010.

[6] C. R. Balistreri, G. Colonna-Romano, D. Lio, G. Candore, and C. Caruso, "TLR4 polymorphisms and ageing: implications for the pathophysiology of age-related diseases," Journal of Clinical Immunology, vol. 29, no. 4, pp. 406-415, 2009.

[7] J. Husemann, J. D. Loike, R. Anankov, M. Febbraio, and S. C. Silverstein, "Scavenger receptors in neurobiology and neuropathology: their role on microglia and other cells of the nervous system," GLIA, vol. 40, no. 2, pp. 195-205, 2002.

[8] C. Nathan and A. Ding, "Nonresolving inflammation," Cell, vol. 140, no. 6, pp. 871-882, 2010.

[9] P. J. Khandelwal, A. M. Herman, and C. E. H. Moussa, "Inflammation in the early stages of neurodegenerative pathology," Journal of Neuroimmunology, vol. 238, no. 1, pp. $1-11,2011$.

[10] C. N. Lumeng, J. L. Bodzin, and A. R. Saltiel, "Obesity induces a phenotypic switch in adipose tissue macrophage polarization," Journal of Clinical Investigation, vol. 117, no. 1, pp. 175-184, 2007.

[11] A. Nimmerjahn, F. Kirchhoff, and F. Helmchen, "Neuroscience: resting microglial cells are highly dynamic surveillants of brain parenchyma in vivo," Science, vol. 308, no. 5726, pp. 1314-1318, 2005.

[12] H. Akiyama, S. Barger, S. Barnum et al., "Inflammation and Alzheimer's disease," Neurobiology of Aging, vol. 21, no. 3, pp. 383-421, 2000.

[13] P. J. Gebicke-Haerter, "Microglia in neurodegeneration: molecular aspects," Microscopy Research and Technique, vol. 54, no. 1, pp. 47-58, 2001.

[14] A. Gerhard, N. Pavese, G. Hotton et al., "In vivo imaging of microglial activation with [11C](R)-PK11195 PET in idiopathic Parkinson's disease," Neurobiology of Disease, vol. 21, no. 2, pp. 404-412, 2006.

[15] K. Ishizawa and D. W. Dickson, "Microglial activation parallels system degeneration in progressive supranuclear palsy and corticobasal degeneration," Journal of Neuropathology and Experimental Neurology, vol. 60, no. 6, pp. 647-657, 2001.

[16] T. M. Dawson and V. L. Dawson, "Molecular pathways of neurodegeneration in Parkinson's disease," Science, vol. 302, no. 5646, pp. 819-822, 2003.

[17] E. Di Maria, M. Tabaton, T. Vigo et al., "Corticobasal degeneration shares a common genetic background with progressive supranuclear palsy," Annals of Neurology, vol. 47, no. 3, pp. 374-377, 2000.

[18] D. W. Dickson, "Tau and synuclein and their role in neuropathology," Brain Pathology, vol. 9, no. 4, pp. 657-661, 1999.

[19] S. M. Lippa, C. F. Lippa, and H. Mori, " $\alpha$-synuclein aggregation in pathological aging and Alzheimer's disease: the impact of $\beta$-amyloid plaque level," American Journal of Alzheimer's Disease and other Dementias, vol. 20, no. 5, pp. 315-318, 2005.
[20] O. Pletnikova, N. West, M. K. Lee et al., “A $\beta$ deposition is associated with enhanced cortical $\alpha$-synuclein lesions in Lewy body diseases," Neurobiology of Aging, vol. 26, no. 8, pp. 11831192, 2005.

[21] A. Popescu, C. F. Lippa, V. M. Y. Lee, and J. Q. Trojanowski, "Lewy bodies in the amygdala: increase of $\alpha$-synuclein aggregates in neurodegenerative diseases with tau-based inclusions," Archives of Neurology, vol. 61, no. 12, pp. 19151919, 2004

[22] D. Yancopoulou, J. H. Xuereb, R. A. Crowther, J. R. Hodges, and M. G. Spillantini, "Tau and $\alpha$-synuclein inclusions in a case of familial frontotemporal dementia and progressive aphasia," Journal of Neuropathology and Experimental Neurology, vol. 64, no. 3, pp. 245-253, 2005.

[23] L. Buée, T. Bussière, V. Buée-Scherrer, A. Delacourte, and P. R. Hof, "Tau protein isoforms, phosphorylation and role in neurodegenerative disorders," Brain Research Reviews, vol. 33, no. 1, pp. 95-130, 2000.

[24] M. Kitazawa, T. R. Yamasaki, and F. M. LaFerla, "Microglia as a potential bridge between the amyloid $\beta$-peptide and tau," Annals of the New York Academy of Sciences, vol. 1035, pp. 85-103, 2004.

[25] Y. Yoshiyama, M. Higuchi, B. Zhang et al., "Synapse loss and microglial activation precede tangles in a P301S tauopathy mouse model," Neuron, vol. 53, no. 3, pp. 337-351, 2007.

[26] P. J. Khandelwal, S. B. Dumanis, A. M. Herman, G. W. Rebeck, and C. E.-H. Moussa, "Wild type and P301L mutant Tau promote neuro-inflammation and $\alpha$-Synuclein accumulation in lentiviral gene delivery models," Molecular and Cellular Neuroscience, vol. 49, no. 1, pp. 44-53, 2012.

[27] Y. Li, L. Liu, S. W. Barger, and W. S. T. Griffin, "Interleukin-1 mediates pathological effects of microglia on tau phosphorylation and on synaptophysin synthesis in cortical neurons through a p38-MAPK pathway," Journal of Neuroscience, vol. 23, no. 5, pp. 1605-1611, 2003.

[28] R. A. Quintanilla, D. I. Orellana, C. González-Billault, and R. B. Maccioni, "Interleukin-6 induces Alzheimer-type phosphorylation of tau protein by deregulating the $\mathrm{cdk} 5 / \mathrm{p} 35$ pathway," Experimental Cell Research, vol. 295, no. 1, pp. 245257, 2004.

[29] E. T. Saez, M. Pehar, M. Vargas, L. Barbeito, and R. B. Maccioni, "Astrocytic nitric oxide triggers tau hyperphosphorylation in hippocampal neurons," In Vivo, vol. 18, no. 3, pp. 275-280, 2004.

[30] T. C. Frank-Cannon, L. T. Alto, F. E. McAlpine, and M. G. Tansey, "Does neuroinflammation fan the flame in neurodegenerative diseases?" Molecular Neurodegeneration, vol. 4, no. 1, article 47, 2009.

[31] T. Wyss-Coray and L. Mucke, "Inflammation in neurodegenerative disease-a double-edged sword," Neuron, vol. 35, no. 3, pp. 419-432, 2002.

[32] B. Cameron and G. E. Landreth, "Inflammation, microglia, and alzheimer's disease," Neurobiology of Disease, vol. 37, no. 3, pp. 503-509, 2010.

[33] J. F. Bazan, K. B. Bacon, G. Hardiman et al., "A new class of membrane-bound chemokine with a CX3C motif," Nature, vol. 385, no. 6617, pp. 640-642, 1997.

[34] J. K. Harrison, Y. Jiang, S. Chen et al., "Role for neuronally derived fractalkine in mediating interactions between neurons and Cx3crl-expressing microglia," Proceedings of the National Academy of Sciences of the United States of America, vol. 95, no. 18, pp. 10896-10901, 1998.

[35] K. Hatori, A. Nagai, R. Heisel, J. K. Ryu, and S. U. Kim, "Fractalkine and fractalkine receptors in human neurons and 
glial cells," Journal of Neuroscience Research, vol. 69, no. 3, pp. 418-426, 2002.

[36] T. Imai, K. Hieshima, C. Haskell et al., "Identification and molecular characterization of fractalkine receptor $\mathrm{C} \times 3 \mathrm{cr} 1$, which mediates both leukocyte migration and adhesion," Cell, vol. 91, no. 4, pp. 521-530, 1997.

[37] Y. Pan, C. Lloyd, H. Zhou et al., "Neurotactin, a membraneanchored chemokine upregulated in brain inflammation," Nature, vol. 387, no. 6633, pp. 611-617, 1997.

[38] O. Yoneda, T. Imai, S. Goda et al., "Fractalkine-mediated endothelial cell injury by NK cells," Journal of Immunology, vol. 164, no. 8, pp. 4055-4062, 2000.

[39] N. Tong, S. W. Perry, Q. Zhang et al., "Neuronal fractalkine expression in HIV-1 encephalitis: roles for macrophage recruitment and neuroprotection in the central nervous system," Journal of Immunology, vol. 164, no. 3, pp. 13331339, 2000.

[40] K. Bhaskar, M. Konerth, O. N. Kokiko-Cochran, A. Cardona, R. M. Ransohoff, and B. T. Lamb, "Regulation of tau pathology by the microglial fractalkine receptor," Neuron, vol. 68, no. 1, pp. 19-31, 2010.

[41] A. E. Cardona, M. E. Sasse, L. Liu et al., "Scavenging roles of chemokine receptors: chemokine receptor deficiency is associated with increased levels of ligand In circulation and tissues," Blood, vol. 112, no. 2, pp. 256-263, 2008.

[42] Z. Liu, C. Condello, A. Schain, R. Harb, and J. Grutzendler, " $\mathrm{C} \times 3 \mathrm{cr} 1$ in microglia regulates brain amyloid deposition through selective protofibrillar amyloid- $\beta$ phagocytosis," Journal of Neuroscience, vol. 30, no. 50, pp. 17091-17101, 2010.

[43] S.-H. Cho, B. Sun, Y. Zhou et al., "Cx3cr1 protein signaling modulates microglial activation and protects against plaque-independent cognitive deficits in a mouse model of Alzheimer disease," Journal of Biological Chemistry, vol. 286, no. 37, pp. 32713-32722, 2011.

[44] S. Kastenbauer, U. Koedel, M. Wick, B. C. Kieseier, H. P. Hartung, and H. W. Pfister, "CSF and serum levels of soluble fractalkine $\left(\mathrm{CX}_{3} \mathrm{CL}_{1}\right)$ in inflammatory diseases of the nervous system," Journal of Neuroimmunology, vol. 137, no. 1-2, pp. 210-217, 2003.

[45] M. Rancan, N. Bye, V. I. Otto et al., "The chemokine Fractalkine in patients with severe traumatic brain injury and a mouse model of closed head injury," Journal of Cerebral Blood Flow and Metabolism, vol. 24, no. 10, pp. 1110-1118, 2004.

[46] B. Sporer, S. Kastenbauer, U. Koedel, G. Arendt, and H. W. Pfister, "Increased intrathecal release of soluble fractalkine in HIV-infected patients," AIDS Research and Human Retroviruses, vol. 19, no. 2, pp. 111-116, 2003.

[47] C. Combadière, C. Feumi, W. Raoul et al., "Cx3cr1dependent subretinal microglia cell accumulation is associated with cardinal features of age-related macular degeneration," Journal of Clinical Investigation, vol. 117, no. 10, pp. 2920-2928, 2007.

[48] R. S. Duan, X. Yang, Z. G. Chen et al., "Decreased fractalkine and increased IP-10 expression in aged brain of APPswe transgenic mice," Neurochemical Research, vol. 33, no. 6, pp. 1085-1089, 2008.

[49] J.-E. Lim, J. Kou, M. Song et al., "MyD88 deficiency ameliorates $\beta$-amyloidosis in an animal model of Alzheimer's disease," American Journal of Pathology, vol. 179, no. 3, pp. 1095-1103, 2011.
[50] S. Lee, N. H. Varvel, M. E. Konerth et al., "Cx3cr1 deficiency alters microglial activation and reduces beta-amyloid deposition in two Alzheimer's disease mouse models," American Journal of Pathology, vol. 177, no. 5, pp. 2549-2562, 2010.

[51] M. Fuhrmann, T. Bittner, C. K. E. Jung et al., "Microglial Cx3 crl knockout prevents neuron loss in a mouse model of Alzheimer's disease," Nature Neuroscience, vol. 13, no. 4, pp. 411-413, 2010.

[52] C. Tromba and I. S. Cohen, "A novel action of isoproterenol to inactivate a cardiac $\mathrm{K}+$ current is not blocked by beta and alpha adrenergic blockers," Biophysical Journal, vol. 58, no. 3, pp. 791-795, 1990.

[53] V. Zujovic, J. Benavides, X. Vigé, C. Carter, and V. Taupin, "Fractalkine modulates TNF- $\alpha$ secretion and neurotoxicity induced by microglial activation," GLIA, vol. 29, no. 4, pp. 305-315, 2000.

[54] C. Limatola, C. Lauro, M. Catalano et al., "Chemokine $\mathrm{CX}_{3} \mathrm{CL}_{1}$ protects rat hippocampal neurons against glutamate-mediated excitotoxicity," Journal of Neuroimmunology, vol. 166, no. 1-2, pp. 19-28, 2005.

[55] O. Meucci, A. Fatatis, A. A. Simen, T. J. Bushell, P. W. Gray, and R. J. Miller, "Chemokines regulate hippocampal neuronal signaling and gp120 neurotoxicity," Proceedings of the National Academy of Sciences of the United States of America, vol. 95, no. 24, pp. 14500-14505, 1998.

[56] T. Mizuno, J. Kawanokuchi, K. Numata, and A. Suzumura, "Production and neuroprotective functions of fractalkine in the central nervous system," Brain Research, vol. 979, no. 1-2, pp. 65-70, 2003.

[57] A. E. Cardona, E. P. Pioro, M. E. Sasse et al., "Control of microglial neurotoxicity by the fractalkine receptor," Nature Neuroscience, vol. 9, no. 7, pp. 917-924, 2006.

[58] A. Denes, S. Ferenczi, J. Halász, Z. Környei, and K. J. Kovács, "Role of $C \times 3 \mathrm{cr} 1$ (fractalkine receptor) in brain damage and inflammation induced by focal cerebral ischemia in mouse," Journal of Cerebral Blood Flow and Metabolism, vol. 28, no. 10, pp. 1707-1721, 2008.

[59] J. Hardy and D. J. Selkoe, "The amyloid hypothesis of Alzheimer's disease: progress and problems on the road to therapeutics," Science, vol. 297, no. 5580, pp. 353-356, 2002.

[60] D. J. Selkoe, "Cell biology of protein misfolding: the examples of Alzheimer's and Parkinson's diseases," Nature Cell Biology, vol. 6, no. 11, pp. 1054-1061, 2004.

[61] J. Hardy, "Alzheimer's disease: genetic evidence points to a single pathogenesis," Annals of Neurology, vol. 54, no. 2, pp. 143-144, 2003.

[62] J. T. Jarrett, E. P. Berger, and P. T. Lansbury, "The carboxy terminus of the $\beta$ amyloid protein is critical for the seeding of amyloid formation: implications for the pathogenesis of Alzheimer's disease," Biochemistry, vol. 32, no. 18, pp. 46934697, 1993.

[63] T. M. J. Allinson, E. T. Parkin, A. J. Turner, and N. M. Hooper, "ADAMs family members as amyloid precursor protein $\alpha$ secretases," Journal of Neuroscience Research, vol. 74, no. 3, pp. 342-352, 2003.

[64] Q. X. Li, C. Maynard, R. Cappai et al., "Intracellular accumulation of detergent-soluble amyloidogenic $A \beta$ fragment of Alzheimer's disease precursor protein in the hippocampus of aged transgenic mice," Journal of Neurochemistry, vol. 72, no. 6, pp. 2479-2487, 1999.

[65] L. Bertram and R. E. Tanzi, "Thirty years of Alzheimer's disease genetics: the implications of systematic meta-analyses," 
Nature Reviews Neuroscience, vol. 9, no. 10, pp. 768-778, 2008.

[66] M. Von Kienlin, B. Künnecke, F. Metzger et al., "Altered metabolic profile in the frontal cortex of PS2APP transgenic mice, monitored throughout their life span," Neurobiology of Disease, vol. 18, no. 1, pp. 32-39, 2005.

[67] S. Oddo, A. Caccamo, I. F. Smith, K. N. Green, and F. M. LaFerla, "A dynamic relationship between intracellular and extracellular pools of A $\beta$," American Journal of Pathology, vol. 168, no. 1, pp. 184-194, 2006.

[68] K. A. Gyure, R. Durham, W. F. Stewart, J. E. Smialek, and J. C. Troncoso, "Intraneuronal A $\beta$-amyloid precedes development of amyloid plaques in Down syndrome," Archives of Pathology and Laboratory Medicine, vol. 125, no. 4, pp. 489-492, 2001.

[69] C. Mori, E. T. Spooner, K. E. Wisniewski et al., "Intraneuronal A $\beta 42$ accumulation in Down syndrome brain," Amyloid, vol. 9, no. 2, pp. 88-102, 2002.

[70] Y. Ohyagi, Y. Tsuruta, K. Motomura et al., "Intraneuronal amyloid $\beta 42$ enhanced by heating but counteracted by formic acid," Journal of Neuroscience Methods, vol. 159, no. 1, pp. 134-138, 2007.

[71] M. P. Burns, L. Zhang, G. W. Rebeck, H. W. Querfurth, and C. E.-H. Moussa, "Parkin promotes intracellular $\mathrm{A} \beta_{1-42}$ clearance," Human Molecular Genetics, vol. 18, no. 17, pp. 3206-3216, 2009.

[72] G. W. Rebeck, H. S. Hoe, and C. E. H. Moussa, “ $\beta$ Amyloid $_{1-42}$ gene transfer model exhibits intraneuronal amyloid, gliosis, tau phosphorylation, and neuronal loss," Journal of Biological Chemistry, vol. 285, no. 10, pp. 74407446, 2010.

[73] C. Pereira, P. Agostinho, P. I. Moreira, S. M. Cardoso, and C. R. Oliveira, "Alzheimer's disease-associated neurotoxic mechanisms and neuroprotective strategies," Current Drug Targets, vol. 4, no. 4, pp. 383-403, 2005.

[74] A. M. Brown, S. J. Finch, and D. Gordon, "Genome-wide association study of genetic loci and Alzheimer disease," Journal of the American Medical Association, vol. 304, no. 8, p. 858, 2010.

[75] P. Hollingworth, D. Harold, R. Sims et al., "Common variants at ABCA7, MS4A6A/MS4A4E, EPHA1, CD33 and CD2AP are associated with Alzheimer's disease," Nature Genetics, vol. 43, no. 5, pp. 429-436, 2011.

[76] J. Rogers, S. Webster, L.-F. Lue et al., "Inflammation and Alzheimer's disease pathogenesis," Neurobiology of Aging, vol. 17, no. 5, pp. 681-686, 1996.

[77] C. Savarin-Vuaillat and R. M. Ransohoff, "Chemokines and chemokine receptors in neurological disease: raise, retain, or reduce?" Neurotherapeutics, vol. 4, no. 4, pp. 590-601, 2007.

[78] J. J. Hoarau, P. Krejbich-Trotot, M. C. Jaffar-Bandjee et al., "Activation and control of CNS innate immune responses in health and diseases: a balancing act finely tuned by neuroimmune regulators (NIReg)," CNS \& Neurological Disorders Drug Targets, vol. 10, no. 1, pp. 25-43, 2011.

[79] K. Rezai-Zadeh, D. Gate, G. Gowing, and T. Town, "How to get from here to there: macrophage recruitment in Alzheimer's disease," Current Alzheimer Research, vol. 8, no. 2, pp. 156-163, 2011.

[80] T. Mizuno, "The biphasic role of microglia in Alzheimer's disease," International Journal of Alzheimer's Disease, vol. 2012, Article ID 737846, 2012.

[81] T. S. Kim, H. K. Lim, J. Y. Lee et al., "Changes in the levels of plasma soluble fractalkine in patients with mild cognitive impairment and Alzheimer's disease," Neuroscience Letters, vol. 436, no. 2, pp. 196-200, 2008.

[82] S. G. Younkin, "The role of A $\beta 42$ in Alzheimer's disease," Journal of Physiology Paris, vol. 92, no. 3-4, pp. 289-292, 1998.

[83] M. Goedert, "Filamentous nerve cell inclusions in neurodegenerative diseases: tauopathies and $\alpha$-synucleinopathies," Philosophical Transactions of the Royal Society B, vol. 354, no. 1386, pp. 1101-1118, 1999.

[84] M. Goedert, "Alpha-synuclein and neurodegenerative diseases," Nature Reviews Neuroscience, vol. 2, no. 7, pp. 492$501,2001$.

[85] D. Lundvig, E. Lindersson, and P. H. Jensen, "Pathogenic effects of $\alpha$-synuclein aggregation," Molecular Brain Research, vol. 134, no. 1, pp. 3-17, 2005.

[86] M. Grazia Spillantini, R. Anthony Crowther, R. Jakes, N. J. Cairns, P. L. Lantos, and M. Goedert, "Filamentous $\alpha$-synuclein inclusions link multiple system atrophy with Parkinson's disease and dementia with Lewy bodies," Neuroscience Letters, vol. 251, no. 3, pp. 205-208, 1998.

[87] M. G. Spillantini, R. A. Crowther, R. Jakes, M. Hasegawa, and M. Goedert, " $\alpha$-Synuclein in filamentous inclusions of Lewy bodies from Parkinson's disease and dementia with Lewy bodies," Proceedings of the National Academy of Sciences of the United States of America, vol. 95, no. 11, pp. 6469-6473, 1998.

[88] M. G. Spillantini and M. Goedert, "The $\alpha$-synucleinopathies: Parkinson's disease, dementia with Lewy bodies, and multiple system atrophy," Annals of the New York Academy of Sciences, vol. 920, pp. 16-27, 2000.

[89] M. G. Spillantini, M. L. Schmidt, V. M. Y. Lee, J. Q. Trojanowski, R. Jakes, and M. Goedert, " $\alpha$-synuclein in Lewy bodies," Nature, vol. 388, no. 6645, pp. 839-840, 1997.

[90] A. Takeda, M. Hashimoto, M. Mallory, M. Sundsumo, L. Hansen, and E. Masliah, "C-terminal $\alpha$-synuclein immunoreactivity in structures other than Lewy bodies in neurodegenerative disorders," Acta Neuropathologica, vol. 99, no. 3, pp. 296-304, 2000.

[91] J. Q. Trojanowski and V. M. Y. Lee, "Parkinson's disease and related $\alpha$-synucleinopathies are brain amyloidoses," Annals of the New York Academy of Sciences, vol. 991, pp. 107-110, 2003.

[92] K. Wakabayashi, K. Matsumoto, K. Takayama, M. Yoshimoto, and H. Takahashi, "NACP, a presynaptic protein, immunoreactivity in lewy bodies in Parkinson's disease," Neuroscience Letters, vol. 239, no. 1, pp. 45-48, 1997.

[93] T. Gasser, "Molecular pathogenesis of Parkinson disease: insights from genetic studies," Expert Reviews in Molecular Medicine, vol. 11, p. e22, 2009.

[94] M. R. Cookson and O. Bandmann, "Parkinson's disease: insights from pathways," Human Molecular Genetics, vol. 19, no. 1, Article ID ddq167, pp. R21-R27, 2010.

[95] D. G. Healy, P. M. Abou-Sleiman, A. J. Lees et al., “Tau gene and Parkinson's disease: a case-control study and metaanalysis," Journal of Neurology, Neurosurgery and Psychiatry, vol. 75, no. 7, pp. 962-965, 2004.

[96] A. Martin-Villalba, M. Hahne, S. Kleber et al., "Therapeutic neutralization of CD95-ligand and TNF attenuates brain damage in stroke," Cell Death and Differentiation, vol. 8, no. 7, pp. 679-686, 2001.

[97] E. J. Benner, R. Banerjee, A. D. Reynolds et al., "Nitrated $\alpha$-synuclein immunity accelerates degeneration of nigral dopaminergic neurons," PLoS ONE, vol. 3, no. 1, Article ID e1376, 2008. 
[98] D. M. Kuhn, D. M. Francescutti-Verbeem, and D. M. Thomas, "Dopamine quinones activate microglia and induce a neurotoxic gene expression profile: relationship to methamphetamine-induced nerve ending damage," Annals of the New York Academy of Sciences, vol. 1074, pp. 31-41, 2006.

[99] A. D. Reynolds, I. Kadiu, S. K. Garg et al., "Nitrated alphasynuclein and microglial neuroregulatory activities," Journal of NeuroImmune Pharmacology, vol. 3, no. 2, pp. 59-74, 2008.

[100] S. S. M. Chin and J. E. Goldman, "Glial inclusions in CNS degenerative diseases," Journal of Neuropathology and Experimental Neurology, vol. 55, no. 5, pp. 499-508, 1996.

[101] P. H. Tu, G. Elder, R. A. Lazzarini, D. Nelson, J. Q. Trojanowski, and V. M. Y. Lee, "Overexpression of the human NFM subunit in transgenic mice modifies the level of endogenous NFL and the phosphorylation state of NFH subunits," Journal of Cell Biology, vol. 129, no. 6, pp. 16291640, 1995.

[102] C. Roodveldt, J. Christodoulou, and C. M. Dobson, "Immunological features of $\alpha$-synuclein in Parkinson's disease," Journal of Cellular and Molecular Medicine, vol. 12, no. 5B, pp. 1820-1829, 2008.

[103] W. Zhang, T. Wang, Z. Pei et al., "Aggregated $\alpha$-synuclein activates microglia: a process leading to disease progression in Parkinson's disease," The FASEB Journal, vol. 19, no. 6, pp. 533-542, 2005.

[104] E. C. Hirsch and S. Hunot, "Neuroinflammation in Parkinson's disease: a target for neuroprotection?" The Lancet Neurology, vol. 8, no. 4, pp. 382-397, 2009.

[105] A. Castaño, A. J. Herrera, J. Cano, and A. Machado, "Lipopolysaccharide intranigral injection induces inflammatory reaction and damage in nigrostriatal dopaminergic system," Journal of Neurochemistry, vol. 70, no. 4, pp. 15841592, 1998.

[106] R. L. Hunter, N. Dragicevic, K. Seifert et al., "Inflammation induces mitochondrial dysfunction and dopaminergic neurodegeneration in the nigrostriatal system," Journal of Neurochemistry, vol. 100, no. 5, pp. 1375-1386, 2007.

[107] M. M. Pabon, A. D. Bachstetter, C. E. Hudson, C. Gemma, and P. C. Bickford, " $\mathrm{CX}_{3} \mathrm{CL}_{1}$ reduces neurotoxicity and microglial activation in a rat model of Parkinson's disease," Journal of Neuroinflammation, vol. 8, article 9, 2011.

[108] S. Shan, T. Hong-Min, F. Yi et al., "NEW evidences for fractalkine/ $\mathrm{CX}_{3} \mathrm{CL}_{1}$ involved in substantia nigral microglial activation and behavioral changes in a rat model of Parkinson's disease," Neurobiology of Aging, vol. 32, no. 3, pp. 443458, 2011.

[109] M. Shi, J. Bradner, A. M. Hancock et al., "Cerebrospinal fluid biomarkers for Parkinson disease diagnosis and progression," Annals of Neurology, vol. 69, no. 3, pp. 570-580, 2011.

[110] B. K. Martin, C. Szekely, J. Brandt et al., "Cognitive function over time in the Alzheimer's disease anti-inflammatory prevention trial (ADAPT): results of a randomized, controlled trial of naproxen and celecoxib," Archives of Neurology, vol. 65, no. 7, pp. 896-905, 2008.

[111] H. M. Gao, B. Liu, W. Zhang, and J. S. Hong, "Novel antiinflammatory therapy for Parkinson's disease," Trends in Pharmacological Sciences, vol. 24, no. 8, pp. 395-401, 2003.

[112] S. M. Allan and N. J. Rothwell, "Cytokines and acute neurodegeneration," Nature Reviews Neuroscience, vol. 2, no. 10, pp. 734-744, 2001.

[113] S. M. Allan, P. J. Tyrrell, and N. J. Rothwell, "Interleukin-1 and neuronal injury," Nature Reviews Immunology, vol. 5, no. 8, pp. 629-640, 2005.
[114] Y. Liu, S. Walter, M. Stagi et al., "LPS receptor (CD14): a receptor for phagocytosis of Alzheimer's amyloid peptide," Brain, vol. 128, no. 8, pp. 1778-1789, 2005.

[115] O. Combarros, J. Infante, E. Rodríguez et al., "CD14 receptor polymorphism and Alzheimer's disease risk," Neuroscience Letters, vol. 380, no. 1-2, pp. 193-196, 2005.

[116] K. Chen, P. Iribarren, J. Hu et al., "Activation of toll-like receptor 2 on microglia promotes cell uptake of alzheimer disease-associated amyloid $\beta$ peptide," Journal of Biological Chemistry, vol. 281, no. 6, pp. 3651-3659, 2006.

[117] M. Fiala, P. T. Liu, A. Espinosa-Jeffrey et al., "Innate immunity and transcription of MGAT-III and Toll-like receptors in Alzheimer's disease patients are improved by bisdemethoxycurcumin," Proceedings of the National Academy of Sciences of the United States of America, vol. 104, no. 31, pp. 1284912854, 2007.

[118] K. L. Richard, M. Filali, P. Préfontaine, and S. Rivest, "Tolllike receptor 2 acts as a natural innate immune receptor to clear amyloid $\beta_{1-42}$ and delay the cognitive decline in a mouse model of Alzheimer's disease," Journal of Neuroscience, vol. 28, no. 22, pp. 5784-5793, 2008.

[119] A. Majumdar, D. Cruz, N. Asamoah et al., "Activation of microglia acidifies lysosomes and leads to degradation of Alzheimer amyloid fibrils," Molecular Biology of the Cell, vol. 18, no. 4, pp. 1490-1496, 2007.

[120] V. Boissonneault, M. Filali, M. Lessard, J. Relton, G. Wong, and S. Rivest, "Powerful beneficial effects of macrophage colony-stimulating factor on $\beta$-amyloid deposition and cognitive impairment in Alzheimers disease," Brain, vol. 132, no. 4, pp. 1078-1092, 2009.

[121] I. Glezer, J. C. Bittencourt, and S. Rivest, "Neuronal expression of $\mathrm{Cd} 36, \mathrm{Cd} 44$, and $\mathrm{Cd} 83$ antigen transcripts maps to distinct and specific murine brain circuits," Journal of Comparative Neurology, vol. 517, no. 6, pp. 906-924, 2009.

[122] G. A. Garden and T. Möller, "Microglia biology in health and disease," Journal of Neuroimmune Pharmacology, vol. 1, no. 2, pp. 127-137, 2006.

[123] A. Stolzing and T. Grune, "Neuronal apoptotic bodies: phagocytosis and degradation by primary microglial cells," The FASEB Journal, vol. 18, no. 6, pp. 743-745, 2004.

[124] A. Witting, P. Müller, A. Herrmann, H. Kettenmann, and C. Nolte, "Phagocytic clearance of apoptotic neurons by microglia/brain macrophages in vitro: Involvement of lectin, integrin-, and phosphatidylserine-mediated recognition," Journal of Neurochemistry, vol. 75, no. 3, pp. 1060-1070, 2000.

[125] M. T. Silva, A. do Vale, and N. M. N. dos Santos, "Secondary necrosis in multicellular animals: an outcome of apoptosis with pathogenic implications," Apoptosis, vol. 13, no. 4, pp. 463-482, 2008.

[126] K. Lauber, S. G. Blumenthal, M. Waibel, and S. Wesselborg, "Clearance of apoptotic cells: getting rid of the corpses," Molecular Cell, vol. 14, no. 3, pp. 277-287, 2004.

[127] Y. Ren and J. Savill, "Apoptosis: the importance of being eaten," Cell Death and Differentiation, vol. 5, no. 7, pp. 563568, 1998.

[128] C. K. Glass, K. Saijo, B. Winner, M. C. Marchetto, and F. H. Gage, "Mechanisms underlying inflammation in neurodegeneration,” Cell, vol. 140, no. 6, pp. 918-934, 2010. 


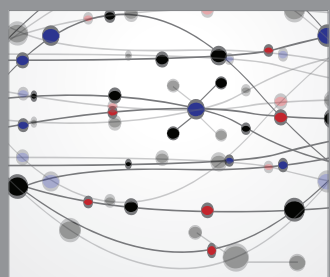

The Scientific World Journal
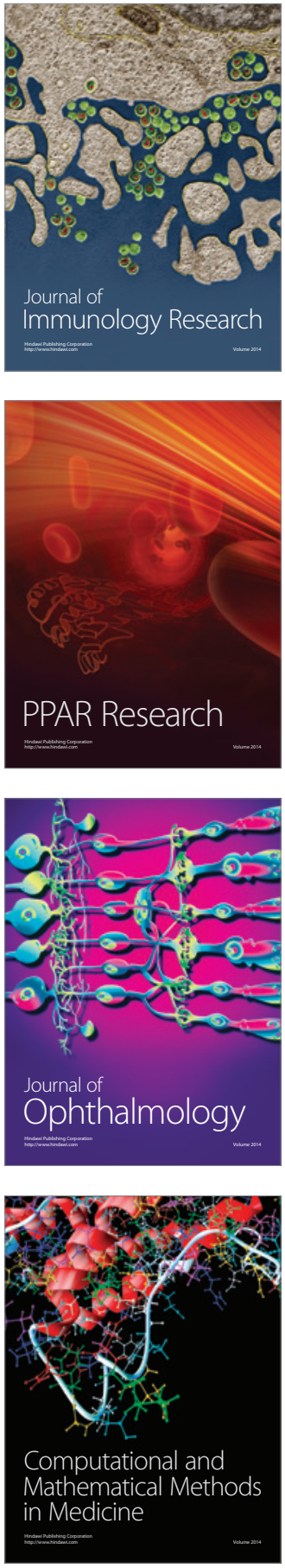

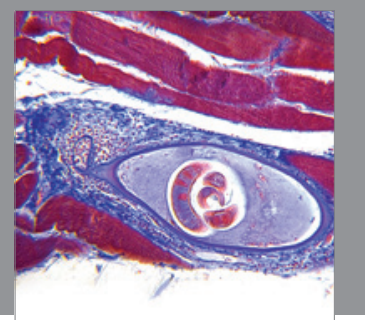

Gastroenterology

Research and Practice
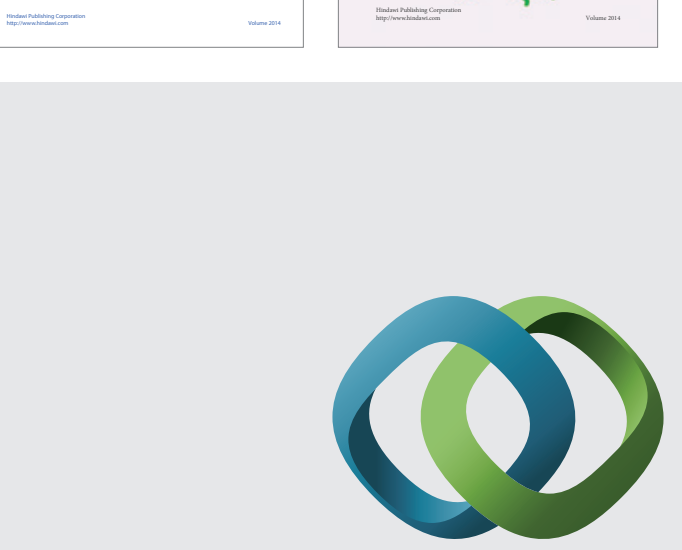

\section{Hindawi}

Submit your manuscripts at

http://www.hindawi.com
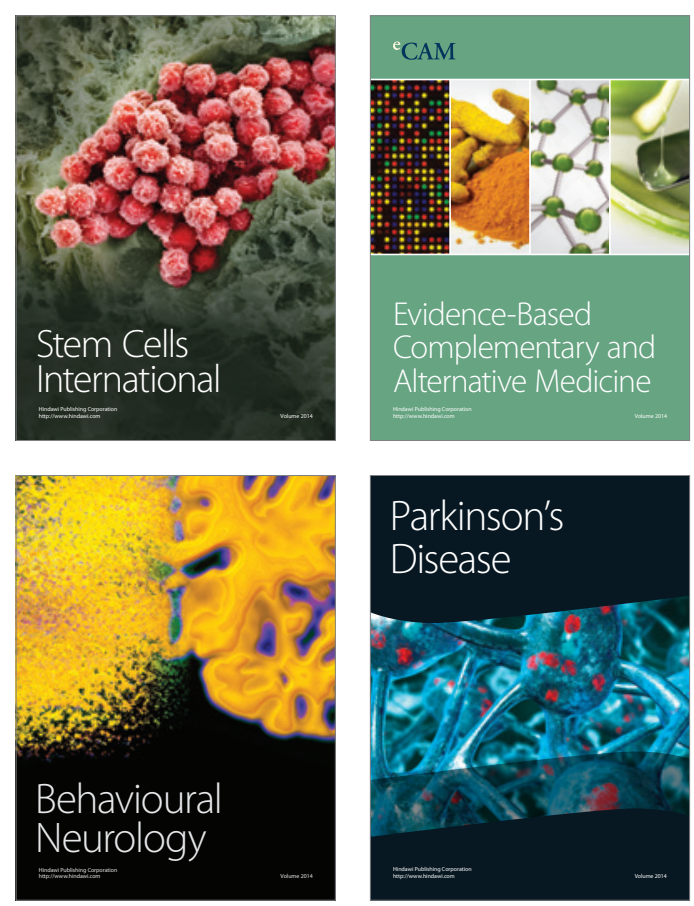

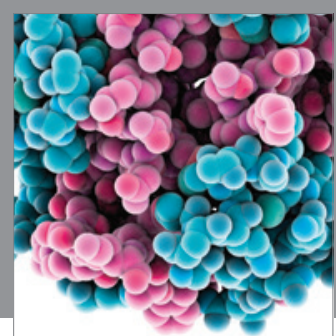

Journal of
Diabetes Research

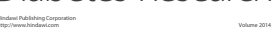

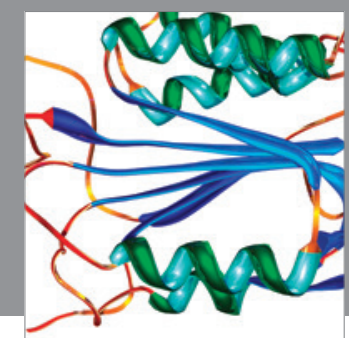

Disease Markers
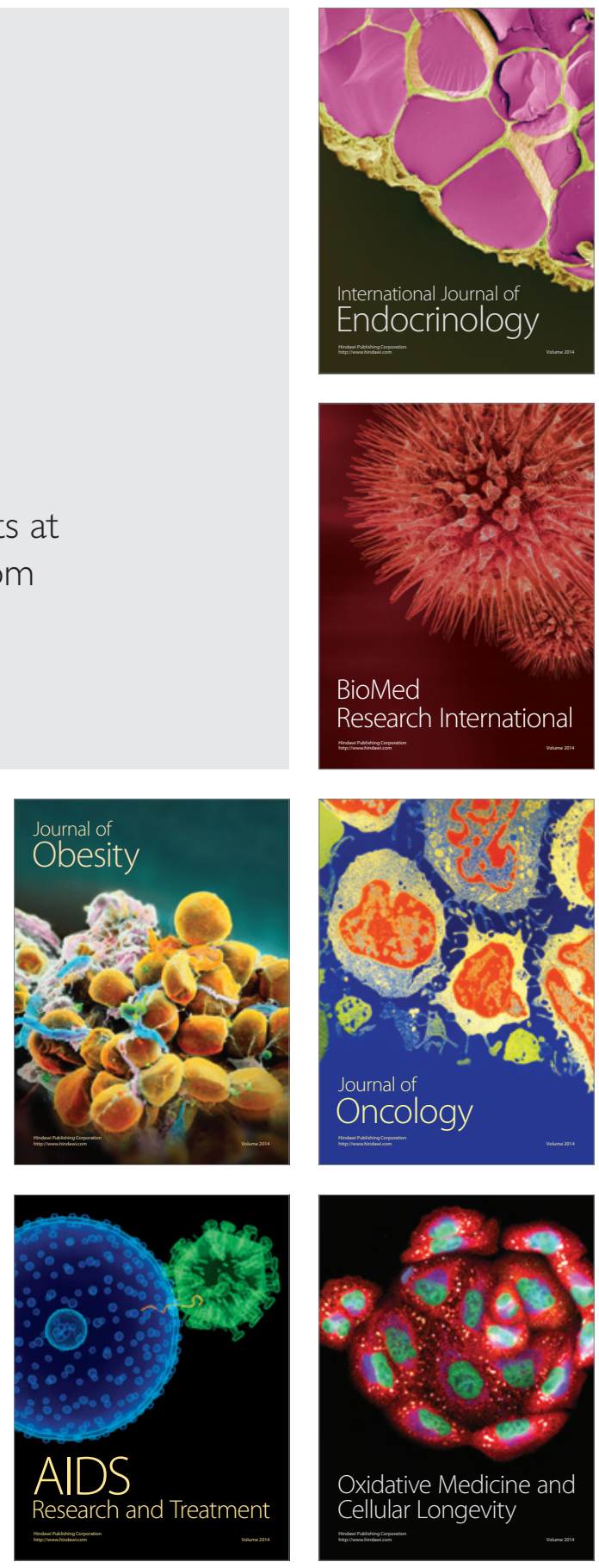